\title{
Helping Preservice Secondary Mathematics Teachers Construct Pedagogical Content Knowledge
}

\author{
Su Liang \\ Correspondence: Su Liang, University of Texas, San Antonio, USA.
}

Received: August 1, 2019

doi:10.11114/ijce.v2i2.4514
Accepted: September 6, 2019

Online Published: September 9, 2019

URL: https://doi.org/10.11114/ijce.v2i2.4514

\begin{abstract}
:
This paper intends to shed light on understanding of Mathematical Pedagogical Content Knowledge (MPCK) from an empirical angle. Examples are utilized to explicitly demonstrate how a class activity in a capstone course of preservice secondary mathematics teachers (PSMTs) could be structured for PSMTs to build MPCK.
\end{abstract}

Keywords: mathematical content knowledge, mathematical pedagogical content knowledge, preservice secondary mathematics teachers, proportional reasoning, appropriate mathematical tasks, active learning, key mathematical ideas

\section{Introduction}

\subsection{MCK and MPCK}

An effective mathematics teacher must have both profound mathematical content knowledge (MCK) and mathematical pedagogical content knowledge (MPCK) (Shulman, 1986, 1987; MA, 1999; Ball, Hill, \& Bass, 2005; Hine, 2015). Existing research described that MCK is understanding of coherent and connected mathematics in depth and breadth (Shulman, 1986; MA 1999, Krauss et al, 2008; Hine, 2015) while MPCK is a knowledge necessary for teachers to be able to craft effective teaching plans to help students gain comprehensive understanding and address potential misunderstandings of certain mathematical ideas/concepts using different forms of representations and explanations (Shulman, 1986; Mayer, 2004a; Beswick \& Goos, 2012). Without solid foundation of MCK, PSTs would face a big hurdle to go further developing MPCK. However, based on the research literature, Krauss et al (2008) argued that the distinction between MCK and MPCK were empirically uncertain even though they were widely accepted in theory. Some researchers believed that MCK and MPCK were highly overlapped in terms of the knowledge for teaching mathematics (Kahan, Cooper, \& Betha, 2003; Hill, Schilling, \& Ball, 2004; Krauss et al, 2008). The large overlapping area of MCK and MPCK makes it difficult for mathematics teacher educators to decide how to help preservice mathematics build MPCK in a mathematics content course.

It is ideal that mathematical content course can help PSTs not only deepen MCK but also develop MPCK according to the theory that effective mathematical teaching needs both adequate MCK and MPCK. Some researchers classified MPCK as knowledge about designing/selecting and implementing mathematical tasks which provide opportunities for students to construct knowledge for learning. However, there is empirical uncertainty in reality as discussed previously. This paper intends to shed light on understanding of MPCK from empirical angle. Examples are utilized to explicitly demonstrate how a class activity in a capstone course of preservice secondary mathematics teachers (PSMTs) could be structured for PSMTs to build MPCK.

\subsection{Reconstructing Preservice Teachers' MCK and Developing Their MPCK}

Research suggested that the knowledge of expert teachers is more extensive and structured in a more connected and integrated way than that of novice teachers (Berliner, 2001; Krauss 2008). Based on this research suggestions, our content courses should help preservice teachers reconstruct their mathematical knowledge in a connected and integrated way. Through the process of knowledge reconstructing preservice teachers' MCK will enriched and deepened while their MPCK will be developed and accumulated. How to make this happen in reality? In order to attain the objective, I propose an approach that is based on key mathematical ideas we design/select appropriate mathematical tasks and implement the tasks with active learning teaching model in mathematics content courses. This paper concentrates on discussing using appropriate mathematical tasks. One set of class activity will be shared and discussed to elucidate how mathematical tasks possibly help PSMTs build MPCK in a capstone mathematics course (CMC). 
CMC is a high division of undergraduate mathematics course offered for PSMTS. Before taking CMC, PSMTs should have taken Calculus, Linear Algebra, Geometry, and Abstract Algebra. Focusing on knowledge integration, CMC activities should be purposely designed to help PSMTs recognize and understand underlying relationships between mathematical ideas/concepts across mathematical topics and grade levels. Here is an example to demonstrate how a class activity can be served for carrying out the proposed idea.

\section{A Sample Set of Class Activities}

\subsection{Recognize the Connections and Development of the Proportional Reasoning Ideas}

Proportional reasoning is one of key mathematical ideas being practiced through elementary, secondary, and college levels of mathematics. To name a few, it includes elementary concepts of fraction, rate and ratio, secondary idea of scaling or slope of a linear function, and rates of change and related rate change in calculus. We can have PSMTs conduct a set of class activities that lead them to recognize the connections and development of the proportional reasoning ideas. Let's look at one set of class activities as below.

1. Use as many ways as you can think of to represent $\frac{3}{4}$ or put it in a relevant context. Your answers could be pictures, graphs, stories, tables, or any other ways you can think of.

2. Write a story that demonstrate $\frac{2}{\frac{2}{3}}=2 \times \frac{3}{2}=3$.

3. Write a story that demonstrate $\frac{\frac{2}{3}}{2}=\frac{2}{3} \times \frac{1}{2}=\frac{1}{3}$.

4. A fifth part of a swarm of bees came to rest on the flower of Kadamba, a third on the flower of Silinda.

Three times the difference between these two numbers flew over a flower of Krutaja, and one bee alone remained in the air, attracted by the perfume of a jasmine in bloom.

Tell me, beautiful girl, how many bees were in the swarm.

(Selected from Lilavati, written for his daughter, by the twelve century AD mathematician Bhaskara). Show both elementary approach and algebraic approach.

5. There is a reservoir with five channels bringing in water. If only the first channel open, the reservoir can be filled in one-third of a day. The second channel by itself will fill the reservoir in 1 day, the third channel in two and one-half days, the fourth one in 3 days, and the fifth one in 5 days. If all the channels are open together, how long will it take to fill the reservoir? (Selected from The Nine Chapter on the Mathematical Art, c.100 BCE - 50 AD). Show both elementary approach and algebraic approach.

6. Cube A has the length of edge $a$. Cube B has the length of edge that doubles the edge of Cube A. Cube C has the length of edge that half the edge of Cube A.

a) What is the ratio of surface area of Cube $\mathrm{B}$ to surface area of Cube $\mathrm{A}$ ?

b) What is the ratio of surface area of Cube $\mathrm{C}$ to surface area of Cube A ?

c) The ratio of volume of Cube $\mathrm{B}$ to volume of Cube $\mathrm{A}$ ?

d) The ratio of volume of Cube $\mathrm{C}$ to volume of Cube $\mathrm{A}$ ?

e) Explain how is the scale factor related to the ratio of cube surface areas and the ratio of cube volumes.

7. Find the slope of $f(x)=x^{2}+1$ at the point $(2,5)$, then find an equation for the line tangent to the graph there.

8. A 10-ft ladder is leaning against a building. The base of the ladder slides away from the wall of the building at $5 \mathrm{ft} / \mathrm{sec}$. How fast is the top of the ladder sliding down from the wall when the base is 6 feet 
from the wall?

9. Reflection. Looking at the problems we solved, how is a rate related to other math ideas/concepts across grades levels? How is a rate used in real life situations? How is the concept "rate" developed in Calculus?

\subsection{Variation of Approach for the Questions}

For the first question, there are some possible answers as examples shown below:

1)

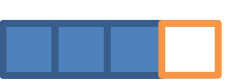

3 out 4: Divide 1 whole strip into 4 equal parts, then mark 3 parts with blue color.

2)

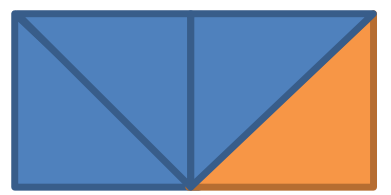

3 out of 4: Divide 1 whole rectangle into 4 equal triangles, then mark 3 triangles with blue color.

3)

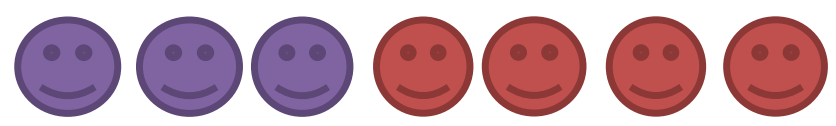

3 to 4 (or 3:4): the ratio between the number of yellow faces and the number of red faces is $\frac{3}{4}$.

4) A class has 36 students, 27 students came to the class today. What portion of the whole class attended the class? $\frac{27}{36}=\frac{3}{4}($ or $75 \%)$ of the class attended the class.

5) Cody and his brother ordered three pizzas yesterday. They ate half of the three pizzas. They want to equally share the leftovers for today's lunch, how much pizza can Cody eat at lunch today?
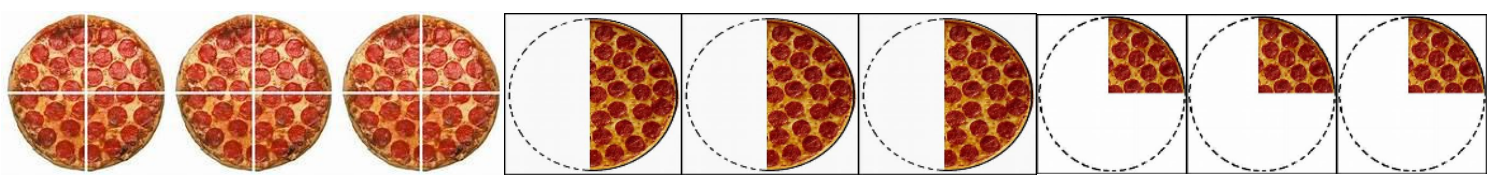

After half of three pizzas were eaten, we have 3 half pizzas or 1 and half pizzas left. Then divide the 3 half pizzas equally for the two brothers, each brother has $\frac{3}{4}$ of one whole pizza. The corresponding mathematical expression is

$$
\left(3-\frac{3}{2}\right) \div 2=\frac{3}{2} \times \frac{1}{2}=\frac{3}{4}
$$

6) Nancy walked $\frac{1}{2}$ of a mile in $\frac{2}{3}$ of an hour. What is Nancy's unit rate of speed in miles per hour?

\begin{tabular}{|c|c|}
\hline$\frac{1}{2}$ mile & $\frac{2}{3}$ \\
& hour \\
\hline$?$ & 1 \\
& hour \\
\hline
\end{tabular}




$$
\begin{aligned}
& \frac{\frac{1}{2}}{x}=\frac{\frac{2}{3}}{1} \\
& x=\frac{1}{2} \text { mile } \div \frac{2}{3} \text { hour }=\frac{1}{2} \times \frac{3}{2}(\text { mile } / \text { hour })=\frac{3}{4} \text { mile } / \text { hour }
\end{aligned}
$$

7)

\begin{tabular}{|l|r|r|r|r|}
\hline $\begin{array}{l}\text { Scoops of ice } \\
\text { cream }\end{array}$ & 2 & 3 & 5 \\
\hline $\begin{array}{l}\text { Teaspoons of } \\
\text { sprinkles }\end{array}$ & $1 \frac{1}{3}$ & $2 \frac{2}{3}$ & 4 & $6 \frac{2}{3}$ \\
\hline
\end{tabular}

$\frac{3}{4}$ is the constant proportionality between scoops of ice between scoops of ice cream and teaspoons of sprinkles.

8) The graph below shows the relationship between a person's number of weeks working and the money saved from each paycheck. Is there a proportional relationship between weeks of working and money saved? Explain the steps you used to find your answer.

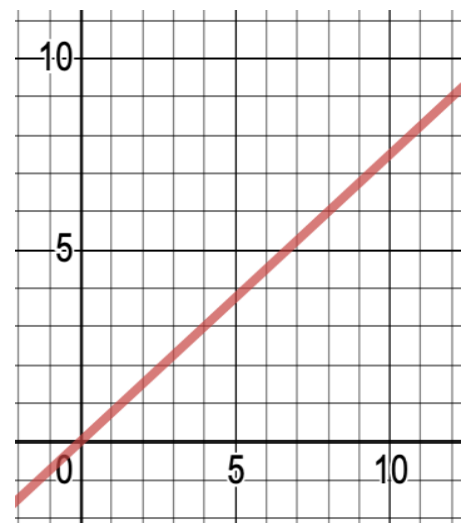

In this graph, horizontal axis represents number weeks working and vertical axis represents the amount of money saved. Select two points $(4,3),(8,6)$ on the line, we can find the slope is $\frac{6-3}{8-4}=\frac{3}{4}$. The graph represent a linear relationship $y=\frac{3}{4} x$

9) Are the rectangle of $6 \mathrm{~cm}$ by $8 \mathrm{~cm}$ and the rectangle of $9 \mathrm{~cm}$ by $12 \mathrm{~cm}$ similar?

Yes, the scale factors of corresponding sides are $\frac{6}{9}=\frac{8}{12}=\frac{3}{4}$. The rectangle of $6 \mathrm{~cm}$ by $8 \mathrm{~cm}$ is shrinking version of the rectangle of $9 \mathrm{~cm}$ by $12 \mathrm{~cm}$ by $\frac{3}{4}$.

10) A spherical balloon is inflated with helium at the rate of $108 \pi i n c h^{3} / \mathrm{min}$. How fast is the balloon's radius increasing at the instant the radius is $6 \mathrm{inch}$ ?

Given that $\frac{d v}{d t}=108 \pi \mathrm{inch}^{3} / \mathrm{min} ; r=6 \mathrm{inch}$ at the instant; find $\frac{d r}{d t}=$ ?

$V=\frac{4}{3} \pi r^{3}, \frac{d v}{d t}=4 \pi r^{2} \frac{d r}{d t}, \frac{d r}{d t}=\frac{\frac{d v}{d t}}{4 \pi r^{2}}=\frac{108 \pi \mathrm{inch}^{3} / \mathrm{min}}{4 \pi 6^{2} \mathrm{inch}^{2}}=\frac{\frac{108}{4 \times 36} \mathrm{inch}}{\min }=\frac{3}{4} \mathrm{inch} / \mathrm{min}$. 


\subsection{Discussion}

There are definitely more possible answers for question 1 than shown examples. In an active learning class, students can form small groups to work on this problem together and then share their solutions in a whole class discussion. The process of finding and sharing a variety of solutions provides opportunities for PSMTs to practice proportional reasoning in different conceptual contexts and construct their mathematical knowledge from integrated perspective in the meantime PSMTs' MPCK would be developed. The class activity intends to pull the mathematics ideas such as fractions, rates, ratios, slopes, the relation between limit definition and the slope of a curve at a point, rates of change, and related rates together through problem-solving in various contexts including real life situations. Question 1 is an open-ended question intended to push PSMT to recall all related knowledge previously learned and think deeply about proportional reasonings across arithmetic, algebra, geometry, and calculus. Question 2 and 3 target on addressing on the common rote memorization of the rule - dividing a fraction is multiplying the reciprocal of the fraction without understanding. Based on my experience of teaching PSMTs for many years, most of PSMTs do not know why dividing a fraction is multiplying the reciprocal of the fraction although they may be able to calculate a division problem involving fractions. My colleagues have the same observation as mine. Only know that $\frac{2}{\frac{2}{3}}=2 \times \frac{3}{2}=3$ is not enough for either solving a sophisticated proportional problem or for teaching the concept effectively. Putting this mathematical process $\frac{2}{\frac{2}{3}}=2 \times \frac{3}{2}=3$ in a real life situation would help PSMTs understand how division is related to multiplication and why dividing a fraction is multiplying the reciprocal of the fraction. The same mathematical process can be demonstrated using many versions of stories. Sharing their solutions will allow PSMTs to see how a problem like this can be meaningful from multiple perspectives in real life and help them understand a mathematical rule can apply to many different settings which have the same mathematical structure although they look like different.

Question \#4 and \#5 are two typical middle-grade proportional reasoning problems selected from two ancient mathematics books. They can be solved either using elementary way by proportional reasoning or algebraic way by setting up an equation. It would be good for PSMTs to see the difference and connection between elementary method and algebraic method. Question \#6 is a geometrical scaling problem in two and three dimensions and can be solved either using properties of similarity or algebraic calculation for finding the ratios between the two surface areas and between the two volumes. This problem offers PSMTs to see how algebra knowledge is used to solve geometrical problem and mathematical topics are not isolated from each other but can be entwined. Question\#7 and \#8 are examples provided for PSMTs to realize how the concept of rate is connected to rates of change and related rates in Calculus and how a mathematical concept is applied across grade levels and different topics. Question \#9 is again an open-ended question which asks PSMTs reflect upon the problems and the process of solving the problems. Research indicates that conscious reflection helps to understand in-depth and adds and enhance meanings to their learning (Helyer, 2015). Gray (2007) suggested that reflection is most effective when the learners share their deep thinking. Just like other problems, PSMTs will be asked to share their reflective ideas and learn from different perspectives.

\section{Conclusion}

In summary, the sample class activity starts and ends with an open-ended question to engage PSMTs in deep thinking and reflective learning from multiple dimensions vertically and horizontally. As the main thread propositional reasoning is the big mathematical idea utilized to connect and integrate mathematics topics across grade levels for solving the problems provided. Through the process of solving the problems PSMTs enrich their MCK and gain PCK at the same time. The diagram below models the structure of this specific class activity. In general, mathematics teacher educators can identify a big mathematical idea (e.g. Equivalence, substation) and use it as a thread to design a class activity for 
PSMTS to deepen their PCK and build their PCK by investigating connected and integrated mathematics. This model can be applied accordingly to preservice elementary teachers' content course.

Future research can investigate the learning outcomes of implementing a class activity structured this way. The research questions could be: 1 . How does this type of class activity evidently help PSMTs restructure their MCK? 2. To what extent does this type of class activity help PSMTs gain MPCK? 3. To what extent does this type of class activity affect PSMTs' self-efficacy on the big mathematics idea addressed? Further empirical studies need to be conducted to answer these questions in order to help mathematics teacher educators see a better picture of MCK and MPCK and develop new professional knowledge for teaching preservice mathematics teachers at both secondary and elementary levels

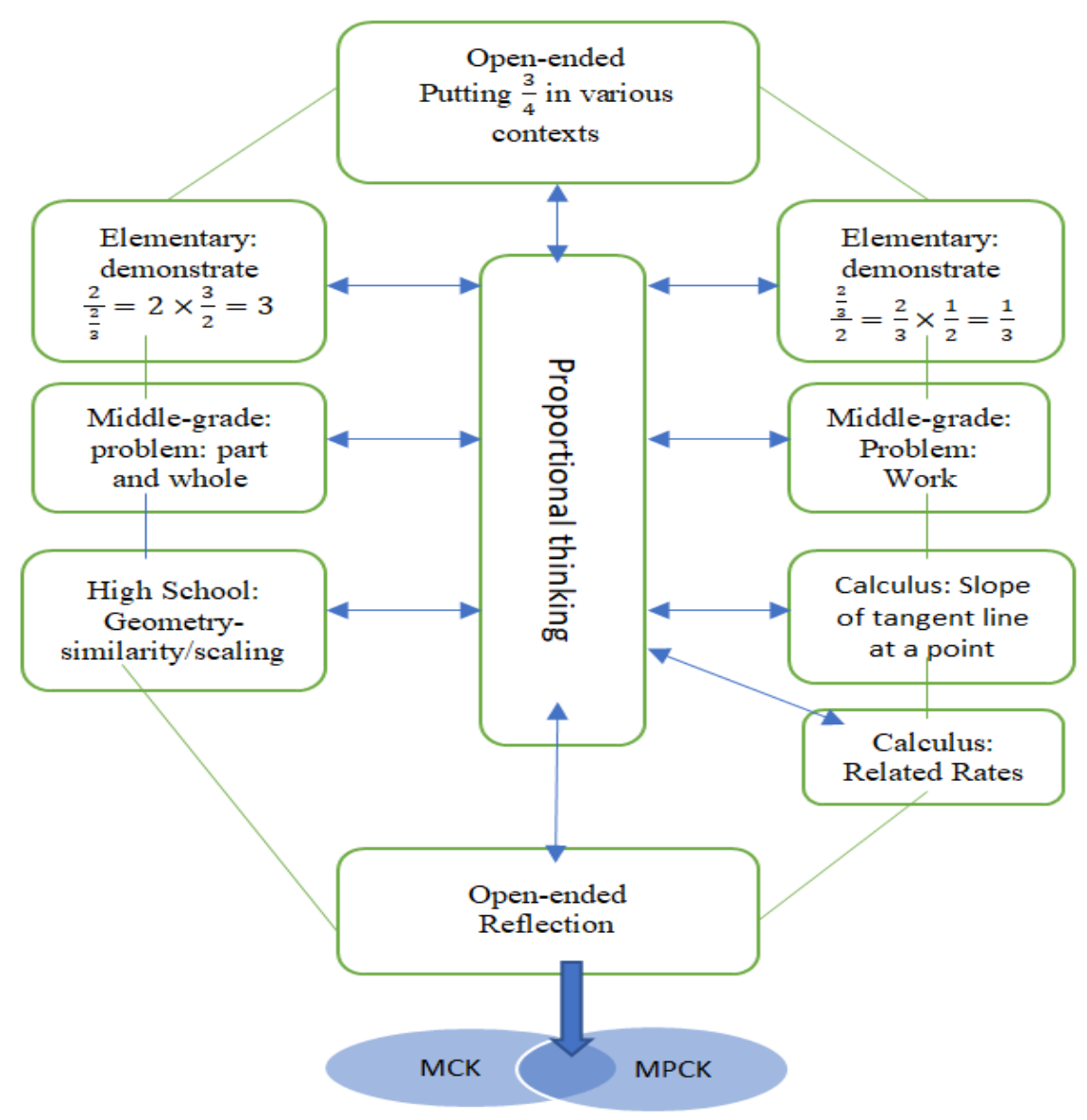

\section{Reference}

Ball, D. L., Hill, H. C., \& Bass, H. (2005, Fall). Knowing mathematics for teaching. American Educator, 14-46.

Berliner, D. C. (2001). Learning about and learning from expert teachers. International Journal of Educational Research, 35, 463-482. https://doi.org/10.1016/S0883-0355(02)00004-6

Beswick, K., \& Goos, M. (2012). Measuring pre-service teachers' knowledge for teaching mathematics. Mathematics Teacher Education and Development, 14(2), 70-90.

Grey, D. E. (2007). Facilitating management learning: developing critical reflection through Reflective tools, Management Learning, 38(5), 495-517. https://doi.org/10.1177/1350507607083204

Helyer, R. (2015). Learning through reflection: the critical role of reflection in work-based learning (WBL), Journal of Work-Applied Management, 7(1), 15-27. https://doi.org/10.1108/JWAM-10-2015-003

Hill, H. C., Schilling, S. G., \& Ball, D. L. (2004). Developing measures of teachers' mathematics knowledge for teaching. Elementary School Journal, 105, 11-30. https://doi.org/10.1086/428763 
Hine, G. S. C. (2015). Strengthening pre-service teachers' mathematical content knowledge. In Teaching and learning uncapped. Proceedings of the 24th Annual Teaching Learning Forum, 29-30 January 2015. Perth: The University of Western Australia. http://ctl.curtin.edu.au/events/conferences/tlf/tlf2015/refereed/geng.pdf

Kahan, J. A., Cooper, D. A., \& Betha, K. A. (2003). The role of mathematics teachers' content knowledge in their teaching: A framework for research applied to a study of student teachers. Journal of Mathematics Teacher Education, 6, 223-252.

Krauss, S., Brunner, M., Kunter, M., Baumert, J., Blum, W., Neubrand, M., \& Joran, A. (2008). Pedagogical Content Knowledge and Content Knowledge of Secondary Mathematics Teachers. Journal of Educational Psychology, 100(3), 716-725.

Ma, L. (1999). Knowing and teaching elementary mathematics. Teachers' understanding of fundamental mathematics in China and the United States. Mahwah, New Jersey: Lawrence Erlbaum Associates Inc.

Mayer, R. E. (2004a). Should there be a three-strikes rule against pure discovery learning? American Psychologist, 59, 14-19. https://doi.org/10.1037/0003-066X.59.1.14

Shulman, L. (1987). Knowledge and teaching: Foundations of the new reform. Harvard Educational Review, 57(1), 1-22. https://doi.org/10.17763/haer.57.1.j463w79r56455411

Shulman, L. S. (1986). Those who understand: Knowledge growth in teaching. Educational Researcher, 15, 4-14. https://doi.org/10.2307/1175860

\section{Copyrights}

Copyright for this article is retained by the author(s), with first publication rights granted to the journal.

This is an open-access article distributed under the terms and conditions of the Creative Commons Attribution license which permits unrestricted use, distribution, and reproduction in any medium, provided the original work is properly cited. 